\title{
Computational Determination of Potential Inhibitors of SARS-CoV-2 Main
}

\section{Protease}

Son Tung Ngo, ${ }^{\text {b }}{ }^{*}$ Ngoc Quynh Anh Pham,${ }^{\mathrm{c}}$ Ly Le, ${ }^{\mathrm{d}}$ Duc-Hung Pham, ${ }^{\mathrm{e}^{*}}$ and Van V. Vu, ${ }^{\mathrm{f}^{*}}$

${ }^{a}$ Laboratory of Theoretical and Computational Biophysics, Ton Duc Thang University, Ho Chi Minh City 700000, Vietnam

${ }^{b}$ Faculty of Applied Sciences, Ton Duc Thang University, Ho Chi Minh City 700000, Vietnam

${ }^{\mathrm{c}}$ Faculty of Chemical Engineering, Ho Chi Minh City University of Technology (HCMUT), Ho

Chi Minh City 700000, Vietnam

${ }^{\mathrm{d} S c h o o l ~ o f ~ B i o t e c h n o l o g y, ~ I n t e r n a t i o n a l ~ U n i v e r s i t y, ~ H o ~ C h i ~ M i n h ~ C i y ~ 700000, ~ V i e t n a m ~}$

'Division of Gastroenterology, Hepatology and NutritionImmunobiology, Cincinnati Children's Hospital Medical Center, Cincinnati 45229, OH, USA

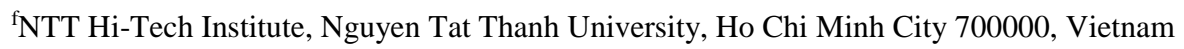

\begin{abstract}
The novel coronavirus (SARS-CoV-2) has infected several million people and caused thousands of deaths worldwide since Dec 2019. As the disease is spreading rapidly all over the world, it is urgent to find effective drugs to treat the virus. The main protease (Mpro) of SARSCoV-2 is one of the potential drug targets. Therefore, in this context, we used rigorous computational methods, including molecular docking, fast pulling of ligand (FPL), and free energy perturbation (FEP), to investigate potential inhibitors of SARS-CoV-2 Mpro. We first tested our approach with three reported inhibitors of SARS-CoV-2 Mpro; and our computational results are in good agreement with the respective experimental data. Subsequently, we applied our approach on a databases of $\sim 4600$ natural compounds, as well as 8 available HIV-1 protease (PR) inhibitors and an aza-peptide epoxide. Molecular docking resulted in a short list of 35 natural compounds,
\end{abstract}


which was subsequently refined using the FPL scheme. FPL simulations resulted in five potential inhibitors, including 3 natural compounds and two available HIV-1 PR inhibitors. Finally, FEP, the most accurate and precise method, was used to determine the absolute binding free energy of these five compounds. FEP results indicate that two natural compounds, cannabisin $A$ and isoacteoside, and an HIV-1 PR inhibitor, darunavir, exhibit large binding free energy to SARSCoV-2 Mpro, which is larger than that of $\mathbf{1 3 b}$, the most reliable SARS-CoV-2 Mpro inhibitor recently reported. The binding free energy largely arises from van der Waals (vdW) interaction. We also found that Glu166 form H-bonds to all the inhibitors. Replacing Glu166 by an alanine residue leads to $\sim 2.0 \mathrm{kcal} / \mathrm{mol}$ decreases in the affinity of darunavir to SARS-CoV-2 Mpro. Our results could contribute to the development of potentials drugs inhibiting SARS-CoV-2. 


\section{INTRODUCTION}

Members of the Coronaviridae virus family often cause mild respiratory syndrome in humans. ${ }^{1}$ However, the severe acute respiratory syndrome coronavirus (SARS-CoV) and the Middle East respiratory syndrome coronavirus (MERS-CoV) are transfected from animals to human and cause severe cases of respiratory syndromes and deaths. ${ }^{2,3}$ In 2002 , SARS-CoV was first recorded in Guandong, China, and linked to 8096 laboratory-confirmed cases of infection and 774 deaths. ${ }^{3}$ The natural reservoir of SARS-CoV is Chinese horseshoe bats ${ }^{4}$ and intermediate hosts are civet cats and raccoon dogs. ${ }^{5}$ This shows that Coronavirus can induce severe symptoms and potential pneumonia and death. In December 2019, a novel coronavirus (2019-nCoV or SARS$\mathrm{CoV}-2$ ) that has similar sequence to SARS-CoV emerged in Wuhan, Hubei province, China. ${ }^{6-8}$ The initial cluster of infection seemed to relate to Huanan seafood market and SARS-CoV-2 is thought to originate from bat though the intermediate hosts are still unknown; ${ }^{9}$ human-to-human transmission has been confirmed. ${ }^{10}$ As of May $7^{\text {th }}, 2020$, SARS-CoV-2 has infected more than $3,800,000$ people and caused over 265,000 deaths worldwide. ${ }^{11}$

Coronaviruses have the largest genomes among all known RNA virus, ranging from 26 $32 \mathrm{~kb}$ in length, which encode structural and non-structural proteins. ${ }^{12,}{ }^{13}$ SARS-CoV-2 genome encodes more than 20 proteins, which include the main protease (Mpro), a 3C-like protease (3CLP) that shares $96,1 \%$ similarity with 3CLP of SARS-CoV. ${ }^{13}, 14$ Mpro, a homodimeric cysteine protease, plays an important role in SARS virus replication and transcription. When the messenger RNA of the virus is translated polyproteins, Mpro is first auto-cleaved to become a mature enzyme, which in turn cleaves all the 11 remaining downstream non-structural proteins of the polyproteins to polypeptides, which are required for the replication process of the virus. ${ }^{13}$ SARS-CoV-2 Mpro 
has thus been an attractive drug target. ${ }^{14,15}$ Darunavir and ritonavir can potentially inhibit SARS-

CoV-2 Mpro and have been put into clinical trials for Covid19 treatment. ${ }^{16,17}$

Computer-aided drug design (CADD) is frequently used to estimate the probable inhibitors that could prevent the activity of an enzyme. This method significantly decreases the time and cost to develop a new drug. ${ }^{18}$ Determination of the ligand-binding free energy is one of the most critical factors in CADD. ${ }^{19}$ Many schemes were then developed to resolve this problem. ${ }^{20}$ Typically, the ligand-binding affinity of several thousand ligands to a protein is frequently predicted via the molecular docking method. ${ }^{21}$; shortlist of these compounds would be then refined via more computationally expensive binding free energy methods such as the molecular mechanism/Poisson-Boltzmann surface area (MM/PBSA), ${ }^{22-24}$ linear interaction energy (LIE) ${ }^{25,}$ ${ }^{26}$ or fast pulling of ligand (FPL) ${ }^{27}$ approaches. The top-lead potential inhibitors will be finally validated through an accurate binding free energy approach such as the free energy perturbation (FEP), ${ }^{28,} 29$ thermodynamic integration (TI), ${ }^{30,} 31$ and non-equilibrium molecular dynamics simulations (NEMD). ${ }^{32}$ Especially, in some cases, calculations required higher accuracy and precision can be conducted via a combination of temperature/Hamiltonian replica exchange molecular dynamics (REMD) simulations and perturbation method. ${ }^{33-36}$ In this work, we carried out computational investigations according to Scheme 1 to evaluate the potential inhibitors for SARS-CoV-2 Mpro. The obtained results could help enhance the development of SARS-CoV-2 therapy.

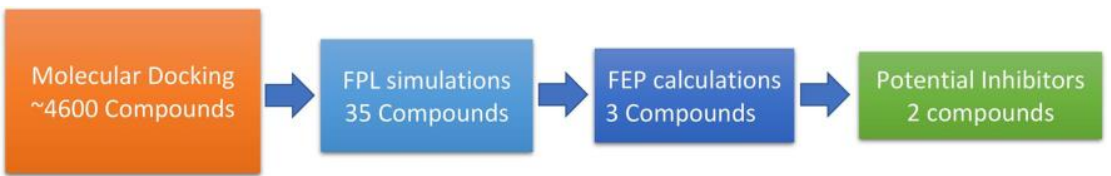

Scheme 1. Computational strategy to determine the probable natural inhibitors of SARS-CoV-2 Mpro. 


\section{MATERIALS \& METHODS}

\section{Structure and Parameter of Complexes}

Three-dimensional structures of SARS-CoV-2 Mpro was downloaded from https://innophore.com/ $/{ }^{37}$ It should be noted that the modelled structure is completely fits to the recent experiment with the $C_{\alpha}$ RMSD is smaller than $0.05 \mathrm{~nm}$ (Figure S1 of SI file). ${ }^{14}$ SARS CoV $2 \mathrm{Mpro}$ was parameterized using Amber99SB ILDN force field. ${ }^{38}$ Ligand structures were downloaded from PubChem database. ${ }^{39}$ The ligands were parameterized with general Amber force field (GAFF) ${ }^{40}$ using the combination of AmberTools $18^{41}$ and ACPYPE ${ }^{42}$ protocols. The atomic eharges were allocated via the Restrained Electrostatic Potential (RESP) method ${ }^{43}$ computed with quantum chemical calculation at B3LYP double-hybrid functional in combination with 6-31G $(\mathrm{d}, \mathrm{p})$ basis set.In addition, the SARS-CoV-2 Mpro is mutated via PyMOL mutagensis tools. ${ }^{38}$

The molecular docking using the Autodock Vina package ${ }^{39}$ was employed to rapidly determine the ligand binding pose and affinity to SARS-CoV-2 Mpro with the exhaustiveness of 8 referring to the previous study. ${ }^{40}$ The parameters of complexes were prepared using AutodockTools 1.5.6, ${ }^{41}$ which parameters-were denoted in the PDBQT file. Particularly, tThe atomic charges of both receptor and ligands were predicted via Gasteiger-Marsili approach. ${ }^{42,43}$ It should be noted that best docking mode was selected as the lowest obtained binding energy results. The grid center was selected as the center of mass of aza-peptide epoxide, which bound to the active site of SARSCoV Mpro. ${ }^{45}$ The grid size was chosen as $26 \times 26 \times 26$ Angstrom.

\section{Molecular Dynamics Simulations}


GROMACS version $5.1 .5^{46}$ was employed to simulate the structural change of the solvated complex SARS-CoV-2 Mpro + inhibitor. The parameters for MD simulations were referred to the previous works. ${ }^{36}$ SARS-CoV-2 Mpro was parameterized using the Amber99SB-ILDN force field. $^{47}$ Ligand structures were downloaded from PubChem database. ${ }^{48}$ The ligands were parameterized with- the general Amber force field $(\mathrm{GAFF})^{49}$ using the combination of ${\underline{\text { AmberTools } 18^{50}}}^{5}$ and $\mathrm{ACPYPE}^{51}$ protocols. The atomic charges were allocated viausing the $\underline{\text { Restrained Electrostatic Potential (RESP) } \text { method }^{52}} \underline{\text { computed with quantum chemical calculation }}$ at B3LYP double-hybrid functional in combination and 6-31G(d,p) basis set. The details of complexed configuration upon applied free energy methods were reported in the next subsection. The time steps of MD simulations were set to $2 \mathrm{fs}$. The electrostatic interaction was mimicked via fast smooth Particle-Mesh Ewald electrostatics method. ${ }^{53}$ The cut-off of the van der Waals interaction was picked asset at $0.9 \mathrm{~nm}$. Moreover, $\mathrm{tThe}$ temperature and pressure couplings were calculated using the V-rescale and Parrinello-Rahman schemes, respectively. Furthermore, Tt $\underline{t h e}$ solvated complex was minimized using the steepest descent method. The energy minimized system was relaxed over 100 ps of NVT and 2 ns of NPT ensembles at $310 \mathrm{~K}$. During the NVT and NPT simulations, $C_{\alpha}$ atoms of the SARS-CoV-2 Mpro was softly retrained using a harmonic force. The coordinates of the solvated complexes were monitored over the atomistic simulations every $10 \mathrm{ps.}$

\section{Free Energy Calculation}

Fast pulling of ligand (FPL) approach. The last snapshot of NPT simulations was used as the initial structure for SMD simulation. ${ }^{27}$ Details of the computations were referred to the previous studies. ${ }^{27}$ In particular, the (x, y, z) dimensions of the systems are $(9.83,5.92,8.70) \mathrm{nm}$ as shown in Figure 1Figure 1. The systems in FPL simulations consists of 1 SARS-CoV-2 Mpro, 1 ligand, water molecules, and $\mathrm{Na}^{+}$ions for a total of ca. 50000 atoms. The pulling speed $(v)$ and spring 
constant cantilever $(k)$ were set at $0.005 \mathrm{~nm} \mathrm{ps}^{-1}$ and $600 \mathrm{~kJ} \mathrm{~mol}^{-1} \mathrm{~nm}^{-2}$, respectively. During the simulations, the $C_{\alpha}$ atoms of Mpro were positionally restrained using a weak harmonic potential. A harmonic force was put on the center of mass of the inhibitor to disassociate it from the binding cavity of the SARS-CoV-2 Mpro (Figure 1Figure 1). The pulling force value and displacement along unbinding direction were monitored every $0.1 \mathrm{ps}$. The FPL simulations were repeated with 8 independent trajectories to guarantee the sampling of simulations.

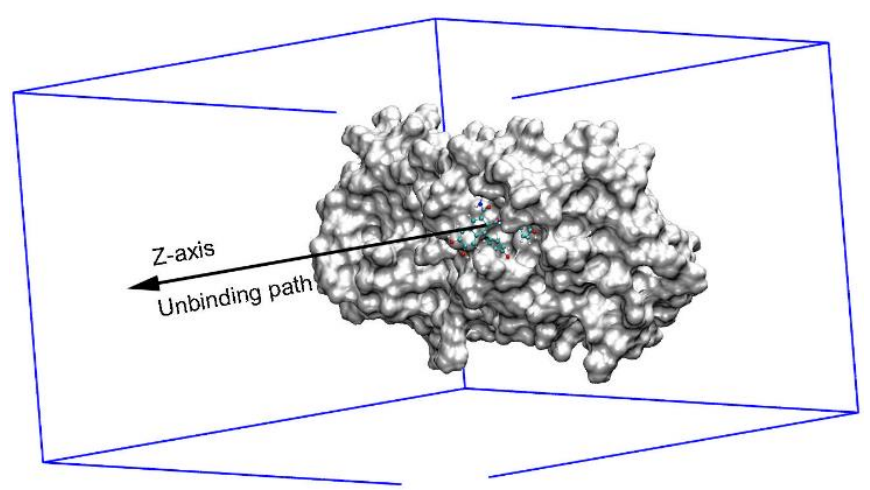

Figure 1. The computational model for FPL simulations of SARS-CoV-2 Mpro - ligand binding affinity.

Free energy perturbation (FEP) simulations. ${ }^{54}$ The last snapshot of NPT simulations was used as the initial conformation for 20 ns-long MD simulations. In particular, the SARS-CoV-2 Mpro + inhibitor complex was inserted into a dodecahedron periodic boundary condition (PBC) box with a volume of ca. $820 \mathrm{~nm}^{3}$. The complexed system comprises 1 SARS-CoV-2 Mpro, 1 ligand, 25 280 water molecules, and $4 \mathrm{Na}^{+}$ions for a total of ca. 80600 atoms. Moreover, the isolated inhibitor was inserted into a dodecahedron PBC box with a volume of ca. $85 \mathrm{~nm}^{3}$. The solvated ligand system consists of 1 ligand and ca. 2750 water molecules for a total of ca. 8300 atoms. The 
equilibrium conformation of MD simulations was then employed as the starting structure for FEP calculations according to the previous study. ${ }^{36}$ During FEP simulations, the coupling parameter $\lambda$, varies from 0 to 1 , was employed to evaluate the free energy change $\Delta G$ of the system modification from the full-interaction state $(\lambda=0)$ to the non-interaction state $(\lambda=1)$ via the alteration of the systemic Hamiltonian between various circumstances. The change of a ligand from full-interaction to non-interaction states with surrounding molecules is called the ligand annihilation process (Figure 2Figure 2). Eight values of $\lambda_{\text {cou }}$, including 0.00, 0.100, 0.20, 0.35, 0.50, 0.65, 0.80, and used to modify the Coulomb interactions. Nine values of $\lambda_{\mathrm{vdW}}$, including 0.000 .100 .250 .350 .50 0.650 .750 .901 .00 , to alter the van der Waals (vdW) interactions. Sixteen alter- $\lambda$ simulations were performed to demolish a ligand from a solvated system (Figure 2Figure 2). The total energy ligand annihilation process was then summed via the Bennet's acceptance ratio (BAR) method. ${ }^{55}$ Finally, the absolute binding free energy between a ligand to SARS-CoV-2 Mpro was deduced as the different energy between two annihilation processes involving decoupling the ligand from the solvated ligand system and from the solvated protein-ligand system.

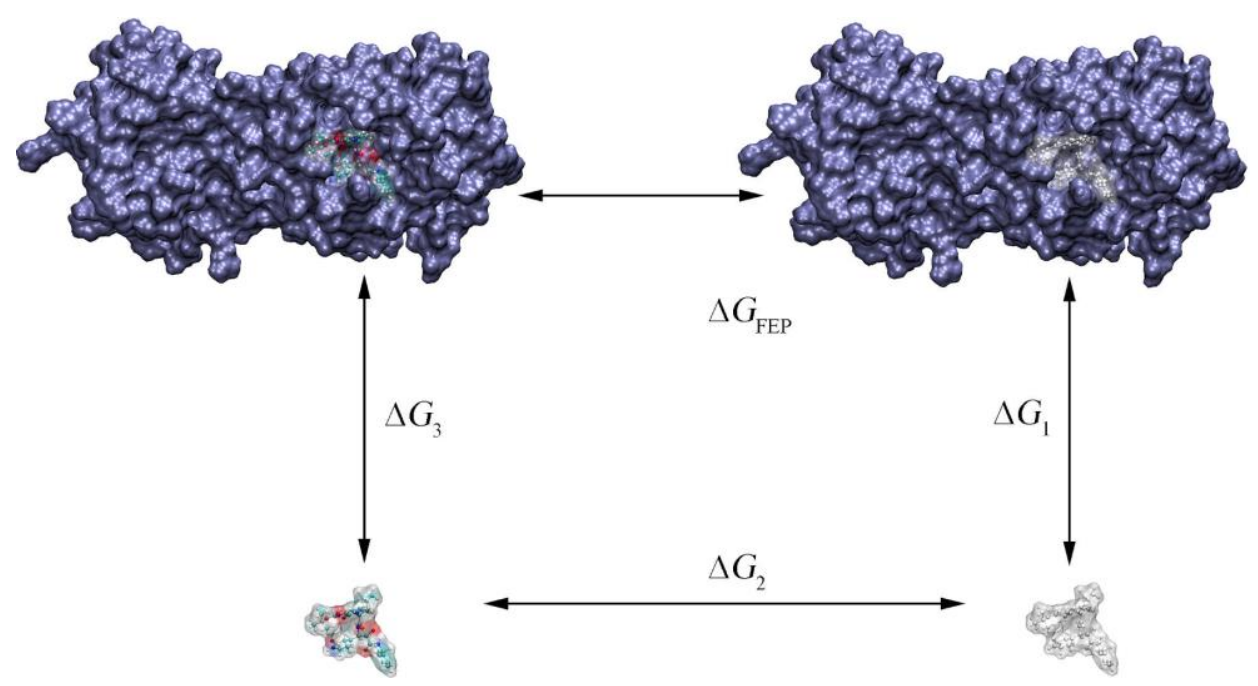


Figure 2. Thermodynamics diagram of determination of the absolute binding free energy between a ligand and SARS-CoV-2 Mpro. A) The full-interaction state of a ligand with surrounding molecules, including the protease and solvent molecules. B) A dummy ligand with the solvated protease. C) The full-interaction state of a ligand with the solvent molecules. D) A dummy ligand in solution. A dummy ligand is a ligand that has no non-bonded interaction with neighboring molecules. The solvent molecules are hidden for clarity.

\section{Structural Analysis}

A hydrogen bond (HB) is determined when an acceptor (A)-hydrogen (H)-donor (D) angle is larger than $135^{\circ}$ and the A - D distance is less than $0.35 \mathrm{~nm}$. A side-chain (SC) contact between inhibitors and SARS-CoV-2 Mpro is counted when the distance between non-hydrogen atoms of two molecules is less than $0.45 \mathrm{~nm}$. The two-dimensional interaction diagram between a protein and a ligand was generated using the LigPlot++ program. ${ }^{56}$ Moreover, pharmacokinetics of the top-lead compounds were predicted using the PreADME server. ${ }^{57}$

\section{RESULTS AND DISCUSSION}

\section{Potential Inhibitor Screening using Molecular Docking}

Autodock Vina ${ }^{39}$ is one of the most popular free packages to roughly and rapidly estimate the binding affinity and binding pose of a ligand to a protein. The successful-docking rate of the package was up to $81 \%$ according to our previous benchmark study on over 800 protein-ligand complexes. ${ }^{40}$ We used Autodock Vina to dock three previously reported ligands ${ }^{14}$ to SARS-CoV2 Mpro and obtained binding energies reasonably consistent to experimentally determined values (Table 1Table 1). Therefore, in this project, Autodock Vina ${ }^{39}$ was employed to rapidly evaluate binding affinity of ca. 4600 natural compounds from the Vietherb database. ${ }^{58}$ Because some 
current HIV-1 PR inhibitors, such as darunavir ${ }^{16}$ or ritonavir, ${ }^{17}$ have been tested for SARS-CoV2 inhibition, eight drugs inhibiting HIV-1 PR, including amprenavir, atazanavir, darunavir, indinavir, lopinavir, nelfinavir, ritonavir, and saquinavir, were also investigated. Moreover, the binding of aza peptide epoxide was also redocked to SARS-CoV-2 Mpro in order to compare with other ligands. The binding affinity of top-lead compounds to SARS-CoV-2 Mpro is provided in Table S1 of the Supporting Information (SI) file, respectively. The obtained docking energies fall the range from -1.2 to $-9.8 \mathrm{kcal} / \mathrm{mol}$ with the median of $-6.22 \pm 0.02 \mathrm{kcal} / \mathrm{mol}$ (the computed error is the standard error of the mean) (Figure 3Figure 3).

\begin{tabular}{c|c|c|c}
\hline $\mathbf{N}^{\mathbf{0}}$ & $\begin{array}{c}\text { Compound } \\
\text { Name }\end{array}$ & $\Delta \boldsymbol{G}_{\text {Dock }}{ }^{\mathbf{a}}$ & $\Delta \boldsymbol{G}_{\text {EXP }}{ }^{\mathbf{b}}$ \\
\hline 1 & $\mathbf{1 1 r}$ & -7.1 & -9.23 \\
2 & $\mathbf{1 3 a}$ & -6.7 & -7.70 \\
3 & $\mathbf{1 3 b}$ & -6.9 & -8.45 \\
\hline
\end{tabular}

a Docking binding free energy obtained by Autodock Vina. ${ }^{39}$ bxperimental binding free energy $\Delta \boldsymbol{G}_{\text {EXP }}$ roughly estimated based on IC50 value reported recently, ${ }^{14}$ assuming that inhibition constant $\left(k_{\mathrm{i}}\right)$ is equal to IC50 value. The unit of $\Delta \mathrm{G}$ is $\mathrm{kCal} / \mathrm{mol}$.

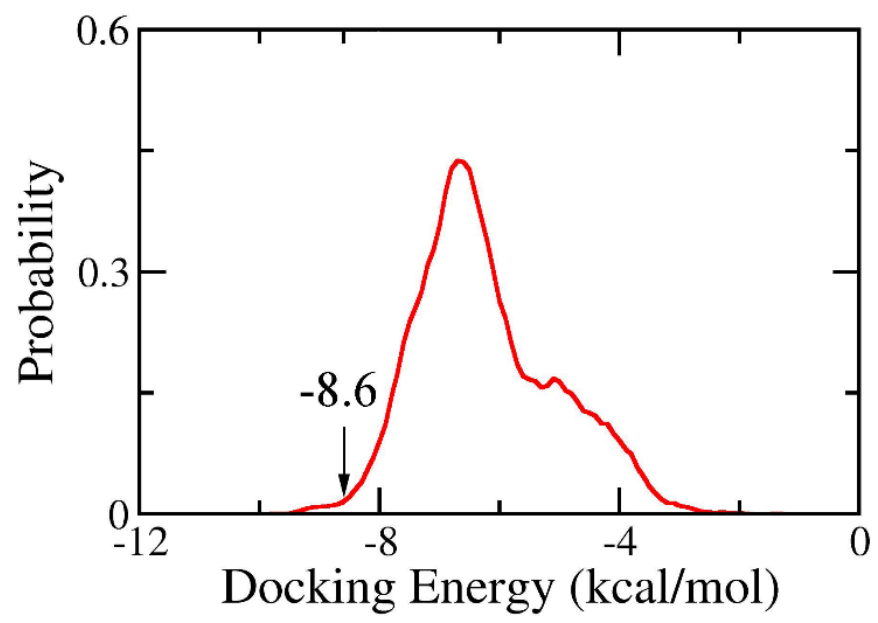

Figure 3. Distribution of docking energy between 4663 natural compounds and SARS-CoV-2 Mpro. 
There are 35 natural compounds from the Vietherb database exhibiting large ligand affinity to SARS-CoV-2 Mpro. The affinity of these compound ranges from -8.6 to $-9.8 \mathrm{kcal} / \mathrm{mol}$ (Table $\mathrm{S} 1 \mathrm{in} \mathrm{SI})$, which is significantly larger than that found in the range of -6.4 to $-7.6 \mathrm{kcal} / \mathrm{mol}$ for the 8 HIV-1 PR inhibitors, and aza peptide epoxide. The 35 natural compounds form more HBs to SARS-CoV-2 Mpro than these 9 compounds (Figure 4Figure 4 and Table S3 of SI).

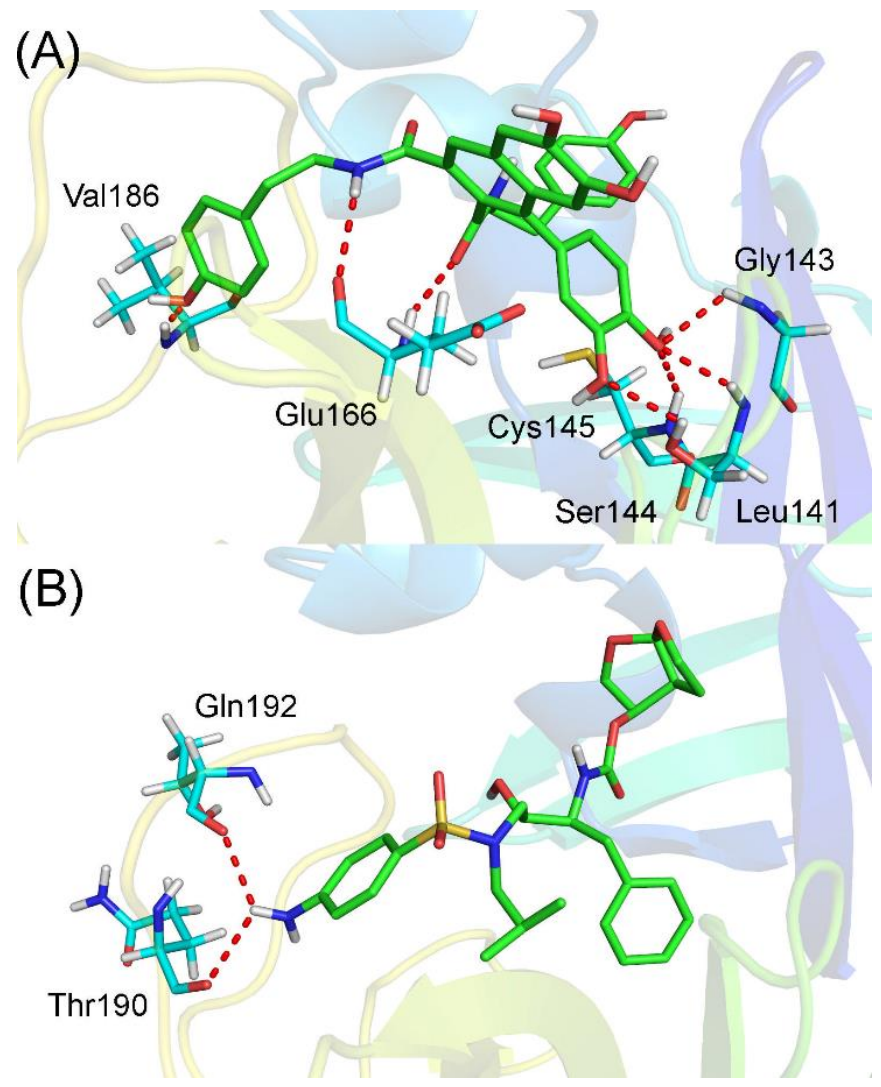

Figure 4. Docked conformations of SARS-CoV-2 Mpro + cannabisin A (A) and SARS-CoV-2 Mpro + darunavir (B) complexes. 


\section{Refining Docking Results using FPL Simulations}

The obtained docking results were refined using the FPL method. ${ }^{27}$ The FPL scheme is a very efficient technique to rapidly explore the binding affinity of a ligand to a protein, when the protein binding cavity accessible to the exogenous ligand without sizable conformational change during the binding/unbinding process. The FPL approach requires a small amount of computing resource, but it could provide results with high accuracy and precision. ${ }^{27}$ The maximum pulling force $\left(F_{\max }\right)$, called rupture force, and the recorded pulling work $(W)$ were used as a criterion to rank the ligand-affinity. ${ }^{27,}{ }^{59}$ However, as mentioned in the previous work, ${ }^{27}$ the pulling work is more appropriate than the rupture force as it directly associates with the ligand-binding free energy via isobaric-isothermal Jarzynski equality. ${ }^{60,61}$

In this work, we carried out FPL simulations to rank the affinity to SARS-CoV-2 Mpro of 44 compounds screened with docking studies. The FPL calculations for $\mathbf{1 1 r}, \mathbf{1 3 a}$, and $\mathbf{1 3} \mathbf{b}^{14}$ were also carried out for comparison. The equilibrated snapshot obtaining from 2 ns of NPT simulations was used as an initial structure for the FPL simulations. The maximum pulling force, called rupture force, and pulling work were obtained from 8 independent trajectories. The obtained results are provided in Table 2Table 2. The mean of recorded rupture forces $F_{\max }$ ranges from $416.9 \pm 35.4$ $\pm 59.2 \mathrm{pN}$. The time-dependent pulling forces of these 47 systems are provided in Figure $\mathrm{S} 3$ of the SI. The form of pulling force curves are in good agreement with the previous studies, ${ }^{27}$ in which the pulling forces continuously increase to maximum values before rapidly dropping to zero after the nonbonded contacts between the ligand to the protein were terminated. Here, the pulling work was selected as a criterion to rank the ligand-affinity (Figure 5Figure 5). The average pulling ranges from $36.1 \pm 4.5$ to $104.0 \pm 5.6 \mathrm{kcal} / \mathrm{mol}$ (Table 2Table 2). The FPL-derived pulling work

13a, 13b is $43.3 \pm 3.9,94.6 \pm 5.0$, and $91.9 \pm 3.6 \mathrm{kcal} / \mathrm{mol}$, respectively, which is consistent with 
respecttive experiments. ${ }^{14}$ This result supports our approach in using FPL to refine the docking results.
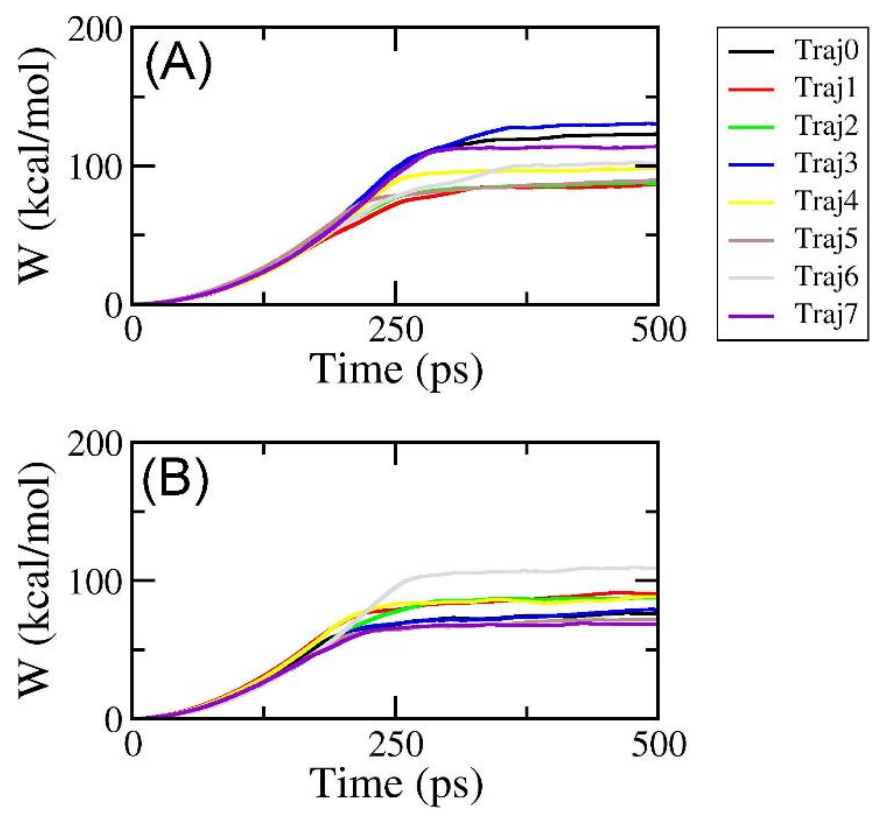

Figure 5. Recorded pulling works during FPL simulations of of SARS-CoV-2 Mpro + cannabisin $A$ (A) and SARS-CoV-2 Mpro + darunavir (B) complexes.

Table 2. FPL results of top-lead compounds screened with molecular docking

\begin{tabular}{c|c|c|c|c|c}
\hline $\mathbf{N}^{\mathbf{0}}$ & Pubchem & Compound Name & $\Delta \boldsymbol{F}_{\mathbf{M a x}}{ }^{\mathbf{a}}$ & $\boldsymbol{W}^{\mathbf{b}}$ & $\Delta \boldsymbol{G}_{\mathbf{E X P}}{ }^{\mathbf{c}}$ \\
1 & & $\mathbf{1 1 r}$ & $857.5 \pm 38.7$ & $94.6 \pm 5.0$ & -9.23 \\
2 & & $\mathbf{1 3 a}$ & $496.0 \pm 32.5$ & $43.3 \pm 3.9$ & -7.70 \\
3 & & $\mathbf{1 3 b}$ & $884.3 \pm 36.5$ & $91.9 \pm 3.6$ & -8.45 \\
4 & 10621 & Hesperidin & $575.6 \pm 46.2$ & $62.7 \pm 4.6$ & \\
5 & 73330 & Strictinin & $633.2 \pm 27$ & $67.9 \pm 3.8$ & \\
6 & 83489 & Eriocitrin & $588.7 \pm 26.8$ & $71.0 \pm 4.8$ & \\
7 & 114777 & CHEMBL346119 & $721.2 \pm 38.1$ & $72.6 \pm 4.5$ & \\
8 & 122738 & Procyanidin B2 & $668.8 \pm 20$ & $77.8 \pm 3.7$ & \\
9 & 124356 & Physalin F & $614.2 \pm 23.5$ & $52.6 \pm 1.8$ & \\
10 & 156766 & Kihadanin B & $500.3 \pm 30.2$ & $45.0 \pm 3.0$ & \\
\hline
\end{tabular}




\begin{tabular}{|c|c|c|c|c|}
\hline 11 & 179651 & Limonin & $516.3 \pm 31.9$ & $45.1 \pm 1.8$ \\
\hline 12 & 183905 & $\begin{array}{c}\text { 6,8-Di-C-Beta-D- } \\
\text { Arabinopyranosyl } \\
\text { Apigenin }\end{array}$ & $672.6 \pm 38.9$ & $67.4 \pm 4.8$ \\
\hline 13 & 190799 & Stephasubine & $807.4 \pm 54.4$ & $78.4 \pm 7.3$ \\
\hline 14 & 196583 & Mulberrofuran G & $674.2 \pm 52.4$ & $71.7 \pm 4.9$ \\
\hline 15 & 442431 & Narirutin & $535.8 \pm 45.3$ & $54.4 \pm 5.1$ \\
\hline 16 & 480819 & Albanol B & $546.6 \pm 27.7$ & $49.7 \pm 3.8$ \\
\hline 17 & 5281600 & Amentoflavone & $710.6 \pm 50.9$ & $74.3 \pm 6.3$ \\
\hline 18 & 5281613 & Diosmin & $714.0 \pm 47.5$ & $77.5 \pm 5.6$ \\
\hline 19 & 5281627 & Hinokiflavone & $645.1 \pm 51.0$ & $67.6 \pm 4.2$ \\
\hline 20 & 5317025 & Linarin & $548.3 \pm 21.9$ & $58.5 \pm 3.0$ \\
\hline 21 & 5319276 & Marchantin K & $567.6 \pm 13.3$ & $50.0 \pm 1.7$ \\
\hline 22 & 5319278 & Marchantin L & $616.1 \pm 34.0$ & $53.9 \pm 3.2$ \\
\hline 23 & 5319933 & Mulberrofuran Q & $539.4 \pm 16.4$ & $54.2 \pm 2.7$ \\
\hline 24 & 5458744 & Physalin B 5,6-Epoxide & $476.2 \pm 32.9$ & $38.4 \pm 3.3$ \\
\hline 25 & 6476333 & Isoacteoside & $730.7 \pm 40.1$ & $92.2 \pm 4.4$ \\
\hline 26 & 6711179 & Hypopistephanine & $707.0 \pm 34.5$ & $65.1 \pm 3.8$ \\
\hline 27 & 9851181 & Isorhoifolin & $567.7 \pm 36.7$ & $57.9 \pm 4.8$ \\
\hline 28 & 10456516 & Cinchonain-Ib & $547.3 \pm 33.7$ & $53.5 \pm 3.1$ \\
\hline 29 & 10461109 & $\begin{array}{l}\text { Luteolin-7-O-Beta- } \\
\text { Rutinoside }\end{array}$ & $608.1 \pm 63.0$ & $65.0 \pm 6.0$ \\
\hline 30 & 11827970 & Diosgenin Glucoside & $514.8 \pm 41.2$ & $49.1 \pm 5.6$ \\
\hline 31 & 15086398 & Cannabisin A & $901.0 \pm 59.3$ & $104 \pm 5.6$ \\
\hline 32 & 16760075 & Didymin & $574.5 \pm 50.9$ & $63.7 \pm 6.0$ \\
\hline 33 & 21123844 & Gamma-Chaconine & $416.9 \pm 35.4$ & $36.1 \pm 4.5$ \\
\hline 34 & 44558930 & Anabsinthin & $589.3 \pm 57.8$ & $56.4 \pm 5.4$ \\
\hline 35 & 71437113 & $\begin{array}{c}2,3- \\
\text { Dihydrohinokiflavone }\end{array}$ & $546.5 \pm 36.1$ & $61.5 \pm 3.3$ \\
\hline 36 & 71448965 & Cannabisin D & $733.1 \pm 32.9$ & $70.4 \pm 4.1$ \\
\hline 37 & 90473381 & N/A & $564.9 \pm 53.0$ & $50.0 \pm 7.1$ \\
\hline 38 & 101764560 & $\begin{array}{l}\text { Quercetin-7-O- } \\
\text { Rutinoside }\end{array}$ & $737.9 \pm 47.8$ & $79.4 \pm 6.4$ \\
\hline 39 & 65016 & Amprenavir & $607.6 \pm 29.9$ & $55.4 \pm 3.7$ \\
\hline 40 & 148192 & Atazanavir & $647.7 \pm 37.9$ & $74.1 \pm 3.3$ \\
\hline 41 & & Aza-Peptide Epoxide & $586.4 \pm 48.2$ & $61.5 \pm 6.4$ \\
\hline 42 & 213039 & Darunavir & $817.8 \pm 32.0$ & $83.9 \pm 4.3$ \\
\hline 43 & 5362440 & Indinavir & $456.3 \pm 33.0$ & $48.5 \pm 1.7$ \\
\hline 44 & 92727 & Lopinavir & $684.8 \pm 44.5$ & $71.2 \pm 3.9$ \\
\hline 45 & 64143 & Nelfinavir & $607.9 \pm 31.5$ & $58.1 \pm 3.0$ \\
\hline 46 & 392622 & Ritonavir & $764.8 \pm 54.0$ & $85.9 \pm 7.8$ \\
\hline 47 & 441243 & Saquinavir & $601.3 \pm 41.6$ & $66.4 \pm 4.4$ \\
\hline
\end{tabular}

${ }^{\mathrm{a}}$ Mean rupture force $\Delta F_{\mathrm{Max}}$ and ${ }^{\mathrm{b}}$ Mean pulling work $W$ obtained from 8 independent trajectories of SMD simulations.

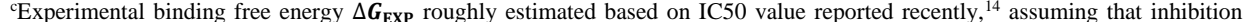
constant $\left(k_{\mathrm{i}}\right)$ is equal to IC50 value. The error is standard error of the mean. The unit of energy and work is $\mathrm{kCal} / \mathrm{mol}$; the unit of force is $\mathrm{pN}$. 
A short list of potential inhibitors of SARS-CoV-2 Mpro was obtained and shown in Table

1Table 1 . The pulling work $W$ for darunavir and ritonavir is 83.9 and $85.9 \mathrm{kcal} / \mathrm{mol}$, respectively, is $>11 \%$ larger than that of the other HIV-1 PR inhibitors (Table 2Table 2). Previous computational investigations suggested that lopinavir was able to prevent SARS-CoV-2 Mpro. ${ }^{62}$ However, FPL results show otherwise, which is consistent with the recent clinical research. ${ }^{63}$ Two natural compounds, cannabisin $A$ and isoacteoside, have larger $W$ values than that of ritonavir. Cannabisin A, Pubchem ID of 15086398 , adopts the largest values of both $W$ and $F_{\max }$, which are $104.0 \mathrm{kcal} / \mathrm{mol}$ and $901.0 \mathrm{pN}$, respectively. Isoacteoside, Pubchem ID of 6476333, has a pulling work $W$ of $92.2 \pm 4.4 \mathrm{kcal} / \mathrm{mol}$. Beside these compounds, quercetin 7-O-Rutinoside was also included into the list of potential inhibitors for the SARS-CoV-2 Mpro, because it adopts a $W$ of $79.4 \pm 6.4 \mathrm{kcal} / \mathrm{mol}$, which is only $5 \%$ small than that of darunavir. These five compounds adopt an appropriate pulling work $W$ in comparison with that obtained for $\mathbf{1 3 b}(91.9 \pm 3.6 \mathrm{kcal} / \mathrm{mol})$, the most reliable SARS-CoV-2 Mpro inhibitor recently reported. ${ }^{14}$

\section{Validation of FPL Results using FEP Calculations}

Accurate and precise determination of the ligand-binding free energy probably reduces drug discovery cost. ${ }^{64}$ Therefore, in order to validate the FPL results, the absolute binding free energy between five ligands was computed using FEP method (Table 3Fable 3), one of the most accurate precise methods known to date. ${ }^{20,65}$ FEP is often used in CADD as it often provides results consistent with experiments. ${ }^{66-68}$ The binding free energy of three recently reported inhibitors of SARS-CoV-2 Mpro, including 11r, 13a, and 13b, was also calculated. The good agreement 
between computational and experimental values ${ }^{14}$ indicates that FEP method is reliable in calculating binding free energy of ligands to SARS-CoV-2 Mpro.

Table 3. Computationally determined potential inhibitors for wild type (WT) and E166A mutants SARS-CoV-2 Mpro

\begin{tabular}{|c|c|c|c|c|c|c|c|}
\hline $\mathbf{N}^{0}$ & $\begin{array}{l}\text { Pubchem } \\
\text { ID }\end{array}$ & Complex & Herb Name & $\Delta \boldsymbol{G}_{\text {cou }}$ & $\Delta \boldsymbol{G}_{\mathrm{vdW}}$ & $\Delta \boldsymbol{G}_{\mathrm{FEP}}{ }^{\mathrm{a}}$ & $\Delta \boldsymbol{G}_{\mathrm{EXP}} \mathrm{b}^{\mathrm{b}}$ \\
\hline 1 & & $\mathrm{WT}+\mathbf{1 1} \mathbf{r}$ & & -6.02 & -7.30 & $-13.31 \pm 2.58$ & -9.23 \\
\hline 2 & & $\mathrm{WT}+\mathbf{1 3 a}$ & & -0.59 & -7.59 & $-8.18 \pm 2.20$ & -7.70 \\
\hline 3 & & $\mathrm{WT}+\mathbf{1 3 b}$ & & -1.97 & -7.22 & $-9.18 \pm 2.48$ & -8.45 \\
\hline 4 & 101764560 & $\mathrm{WT}+$ Quercetin 7-O-Rutinoside & $\begin{array}{l}\text { Platycodon } \\
\text { Grandiflorum }\end{array}$ & -3.82 & -9.33 & $-5.52 \pm 1.18$ & \\
\hline 5 & 15086398 & $\mathrm{WT}+$ Cannabisin $A$ & Cannabis Sativa & -2.57 & -10.20 & $-12.76 \pm 1.37$ & \\
\hline 6 & 6476333 & $\mathrm{WT}+$ Isoacteoside & $\begin{array}{l}\text { Fernandoa } \\
\text { Adenophylla }\end{array}$ & -2.06 & -7.34 & $-9.40 \pm 2.64$ & \\
\hline 7 & 213039 & $\mathrm{WT}+$ Darunavir & & -3.44 & -8.52 & $-11.96 \pm 1.99$ & \\
\hline 8 & 392622 & $\mathrm{WT}+$ Ritonavir & & 2.10 & -9.83 & $-7.73 \pm 1.77$ & \\
\hline 9 & 213039 & E166A + Darunavir & & -1.58 & -8.32 & $-9.90 \pm 2.48$ & \\
\hline
\end{tabular}

${ }^{\mathrm{a}}$ Absolute binding free energy $\Delta \boldsymbol{G}_{\mathrm{FEP}}$ obtained using 3 independent FEP calculations. ${ }^{\mathrm{b}}$ Experimental binding free energy $\Delta \boldsymbol{G}_{\mathrm{EXP}}$ roughly estimated based on IC50 value reported recently, ${ }^{14}$ assuming that inhibition constant $\left(k_{\mathrm{i}}\right)$ is equal to IC50 value. The error is standard error of the mean values. The unit of energy and work is $\mathrm{kcal} / \mathrm{mol}$.

The equilibrium snapshots of the SARS-CoV-2 Mpro + inhibitor systems generated in NPT simulations were treated as the initial conformations for MD simulations. These MD simulations were set to run for $20 \mathrm{~ns}$, in which all-atom RMSD of the complex was recorded every $10 \mathrm{ps}$ (Figure S4 of the SI). During the MD simulations, the binding pose between the SARS-CoV-2 Mpro and the inhibitor was refined under the effects of the interaction among them. The number of HBs between protein-ligand fluctuates from the beginning of MD simulations and becomes stables after $10 \mathrm{~ns}$ of MD simulations (Figure 6Figure 6). It is consistent with all-atom RMSD of the complex over the MD simulations (Figure S4 of the SI). Figure 7Figure 7 shows the dominant structures and binding poses of cannabisin A and darunavir with SARS-CoV-2 Mpro, respectively. The poses for for SARS-CoV-2 Mpro + isoacteoside, quercetin 7-o-rutinoside, and ritonavir complexes are provided in Figure S5-7 of the SI. Interestingly, Glu166 appears to be an important residue involving in the binding of the inhibitors to SARS-CoV-2 Mpro as it forms HBs with all 
of these inhibitors. The mutation of Glu166 could possibly alter the affinity of inhibitors to SARS-

CoV-2 Mpro.
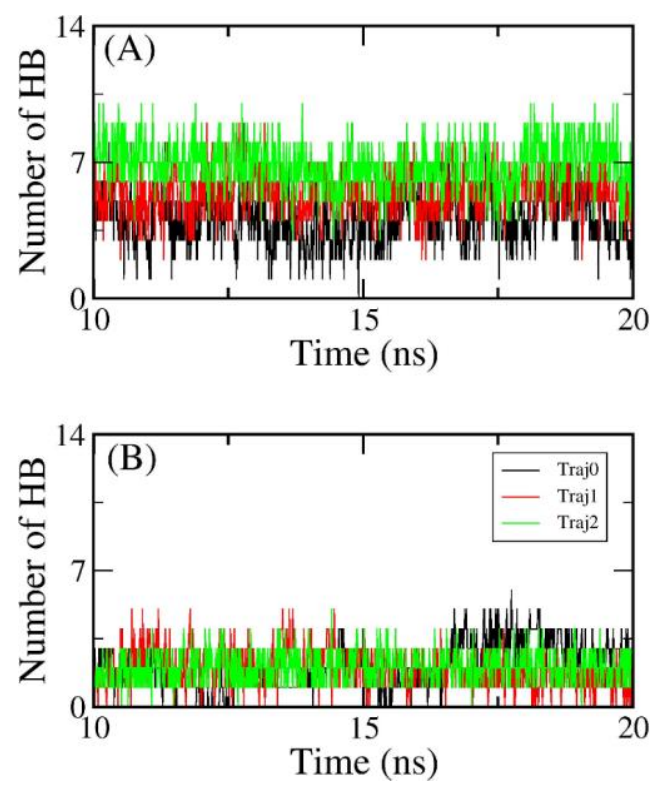

Figure 6. The number of HBs between SARS-CoV-2 Mpro and cannabisin A (A) and darunavir (B) over equilibrium region of MD simulations. 

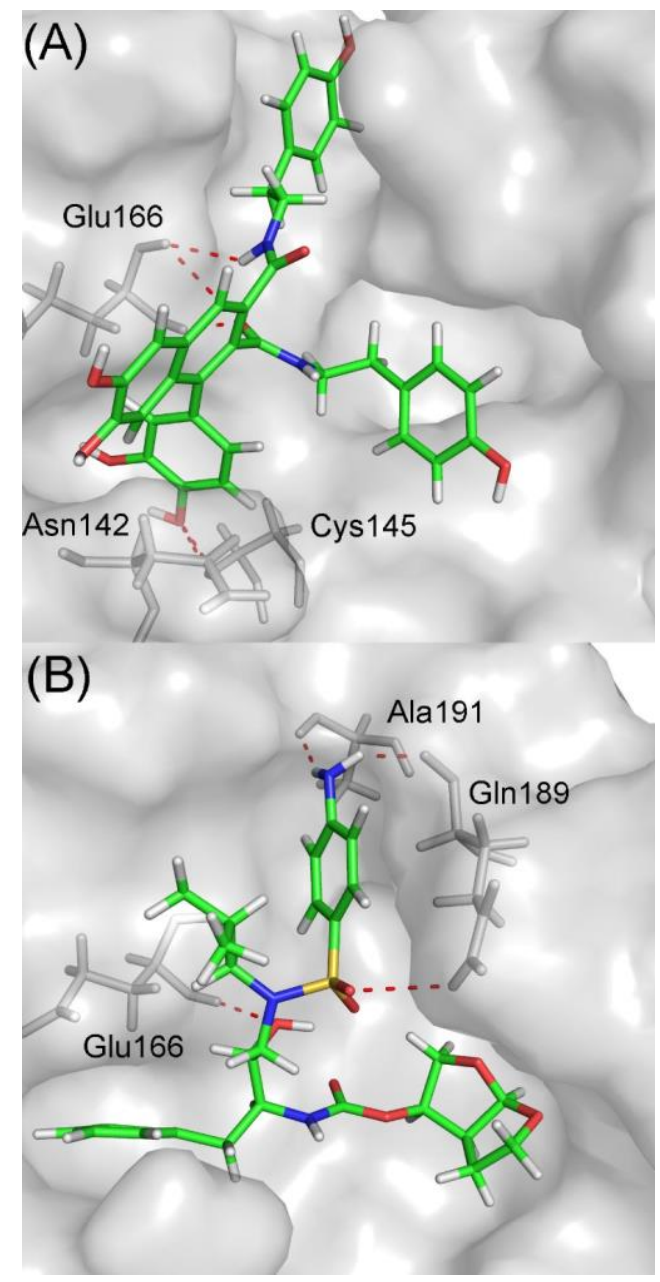

Figure 7. The binding pose of the SARS-CoV-2 Mpro + cannabisin A (A) and SARS-CoV-2 Mpro + darunavir (B) systems, obtained by all-atom clustering with a cutoff $0.3 \mathrm{~nm}$ using 3000 equilibrium snapshots.

The work values of the decoupling ligand from the solvated system are used to determine the free energy change over the annihilation ligand process (Figure 2Figure 2). Sixteen $\lambda$ simulations length of $2 \mathrm{~ns}$ were employed to calculate the work values. The soft-core potentials 
were used to characterize the altered Hamiltonian system. However, the soft-core potentials cost much more CPU time than the traditional one. Therefore, the performance of MD simulation is significantly reduced during $\lambda$-alteration simulations. Totally, MD simulations were carried out in 219 ns over 3 trajectories. The free energy terms were then computed using the BAR method ${ }^{55}$ over the interval $1-2 \mathrm{~ns}$ of the $\lambda$-alteration simulations with a period of $100 \mathrm{ps}$. Overall, the absolute binding free energy between five potential inhibitors to SARS-CoV-2 Mpro was then obtained (Table 3Table 3).

According to results showing in Table 3Table 3, the vdW free energy interaction energy over the electrostatic free interaction energy during a ligand binding to SARS-CoV-2 Mpro. Moreover, darunavir adopts a stronger binding free energy $(-11.96 \pm 1.99 \mathrm{kcal} / \mathrm{mol})$ to SARSCoV-2 Mpro than ritonavir $(-7.73 \pm 1.77 \mathrm{kcal} / \mathrm{mol})$. This result is consistent with recent clinical $\operatorname{research}^{63}$ that ritonavir only has weak inhibitory effect on SARS-CoV-2.

Quercetin 7-o-rutinoside, a compound from platycodon grandiflorum, ${ }^{58}$ exhibits poor binding affinity SARS-CoV-2 Mpro (-5.52 $\pm 1.18 \mathrm{kcal} / \mathrm{mol})$. Isoacteoside, a compound from fernandoa adenophylla ${ }^{58}$ has an binding affinity of $-9.40 \pm 2.64 \mathrm{kcal} / \mathrm{mol}$, which falls between that of ritonavir and darunavir. Cannabisin A, a compound from cannabis sativa, ${ }^{69}$ adopts the strongest binding affinity to the SARS-CoV-2 Mpro $(-12.76 \pm 1.37 \mathrm{kcal} / \mathrm{mol})$.

FEP result suggests that canabisin A, isoacetoside, and darunavir are the potential inhibitors for SARS-CoV-2 Mpro since their binding free energies are larger than that of compound $\mathbf{1 3 b}$, has a computational binding free energy of $-9.18 \pm 2.48 \mathrm{kcal} / \mathrm{mol}$ (Table 3 Fable addition, the cell membrane crossing ability was then predicted for these compounds using the preADMET server. The $\log \mathrm{P}$ values predicted for Canabisin $A$ is 5.18 , which is similar to that of ritonavir (5.59) and higher than that of darunavir (2.22). Having a $\log \mathrm{P}$ value similar to an 
approved drug further supports canabisin $A$ as a potential drug for SARS-CoV-2. In addition, the predicted $\log \mathrm{P}$ value of isoacetoside is relatively small but is still on the positive side and should still be included in future study.

\section{Potential Key residue in SARS-CoV-2 Mpro-ligand binding}

The potential important residues in SARS-CoV-2 Mpro-ligand binding are probablycould be probed via estimating the probabilities of SC and HB contacts between high-affinity inhibitors and individual residues of SARS-CoV-2 Mpro (ef. $\underline{\mathbf{8}}$ Figure 8). Particularly, the residues His41, N142, S144, C145, H164, M165, E166, L167, and Q189 formed SC contacts to the inhibitors in more than ever $80 \%$ of MD equilibrium snapshots. However, innterestingly, the inhibitors only to Glu166 over $81 \%$ of MD equilibrium snapshots. As mentioned above, residue Glu166 is located alters the binding affinity of a ligand to SARS-CoV-2 Mpro. To test this hypothesis, we have replaced Glu166 with an alanine residue and carried FEP calculation for E166A SARS-CoV-2 Mpro + darunavir complex (Table 1). Upon E166A mutation, the calculated binding affinity of darunavir to SARS-CoV-2 Mpro changes from $-11.96 \pm 1.99 \mathrm{kcal} / \mathrm{mol}$ to $-9.90 \pm 2.48 \mathrm{kcal} / \mathrm{mol}$. This $\sim 2 \mathrm{kcal} / \mathrm{mol}$ decreases in binding affinity mostly arises from the weakening in coulomb interaction $\left(\Delta G_{c o u}\right)$ due to the loss of HBs formed by the residue 166 . This result suggest that G166 is potentially a key residue in ligand binding to SARS-CoV-2, and its mutation to hydrophobic residue could lead to decreases in inhibitory effect of ligands. 

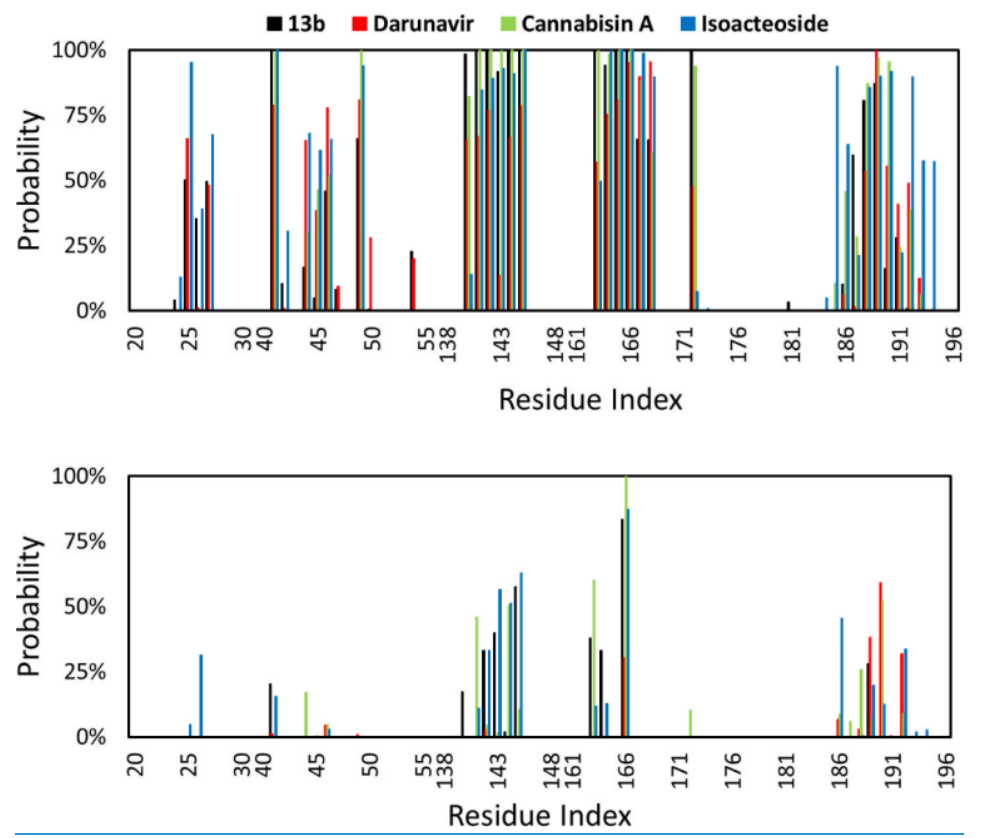

Figure 8. Probabilities of SC (topup) and HB (downottom) contacts between high-affinity SARS-CoV-2 Mpro over 3000 MD equilibrium snapshots-of MD simulations.

\section{CONCLUSIONS}

In this work, we utilized a rigorous computational approach to determine potential inhibitors of SARS-CoV-2 Mpro. First, we tested our approach on 3 recently reported inhibitors of SARS-CoV-2 Mpro and obtained computational results consistent with the experimental data. Subsequently, we investigated a database of 4600 natural compounds found in Vietnamese plants (Vietherbs). Eight HIV-1 PR inhibitors and an aza-peptide epoxide were added to the database. The database was first shortlisted to 44 by molecular docking, which was further refined using FPL simulations to 5 compounds. The refined compounds were validated with FEP method, the most accurate binding free energy estimation method. We found that 2 two natural compounds, 
cannabisin A and isoacteoside, in the Vietherbs database and an HIV-1 PR inhibitors, darunavir, can potentially inhibit SARS-CoV-2 Mpro since their affinities are significantly larger than that of the compound $\mathbf{1 3 b}$, a most reliable SARS-CoV-2 inhibitors from the recent work. ${ }^{14}$ Moreover, the others HIV-1 PR inhibitors are unlikely to prevent SARS-CoV-2 Mpro, consistent with a recent clinical study. ${ }^{63}$ Furthermore, we also found that the residue Glu166 possibly plays an important role in the binding of a ligand to SARS-CoV-2 Mpro, which could be a target for future study.

\section{ASSOCIATED CONTENT}

\section{Supporting Information}

Supporting Information Available: List of top-lead inhibitors for SARS-CoV-2 Mpro obtained via molecular docking; two-dimensional protein-ligand interaction diagram of top-lead compounds; superposition of modelled and experimental SARS-CoV-2 Mpro; superposition of experimental and docked conformations of the compound 13b; FPL results; all-atom RMSD of SARS-CoV-2 Mpro + inhibitor systems; binding pose between SARS-CoV-2 Mpro + isoacteoside/quercetin 7o-rutinoside/ritonavir obtained via MD simulations; and a docking list of all compounds to SARS-

CoV-2 Mpro. This material is available free of charge via the Internet at http://pubs.acs.org.

\section{AUTHOR INFORMATION}

\section{Corresponding Author}

*Email: ngosontung@tdtu.edu.vn; duchung.pham@cchmc.org and vanvu@ntt.edu.vn

\section{Author Contributions}


STN, DHP, and VVV designed studies and wrote the manuscript. STN and NQAP performed and analyzed data. LL collected the structures of natural compounds.

\section{Notes}

The authors declare no competing financial interests.

\section{ACKNOWLEDGMENT}

This work was supported by Vietnam National Foundation for Science \& Technology

Development (NAFOSTED) grant \#104.99-2019.57.

\section{REFERENCES}

1. Hoffmann, M.; Kleine-Weber, H.; Schroeder, S.; Krüger, N.; Herrler, T.; Erichsen, S.; Schiergens, T. S.; Herrler, G.; Wu, N.-H.; Nitsche, A.; Müller, M. A.; Drosten, C.; Pöhlmann, S., SARS-CoV-2 Cell Entry Depends on ACE2 and TMPRSS2 and Is Blocked by a Clinically Proven Protease Inhibitor. Cell 2020, 181, 1-10.

2. Fehr, A. R.; Channappanavar, R.; Perlman, S., Middle East Respiratory Syndrome: Emergence of a Pathogenic Human Coronavirus. Annu. Rev. Med. 2017, 68, 387-399.

3. de Wit, E.; van Doremalen, N.; Falzarano, D.; Munster, V. J., SARS and MERS: recent insights into emerging coronaviruses. Nat. Rev. Microbiol. 2016, 14, 523-534.

4. Lau, S. K. P.; Woo, P. C. Y.; Li, K. S. M.; Huang, Y.; Tsoi, H.-W.; Wong, B. H. L.; Wong, S. S. Y.; Leung, S.-Y.; Chan, K.-H.; Yuen, K.-Y., Severe acute respiratory syndrome coronavirus-like virus in Chinese horseshoe bats. Proc. Natl. Acad. Sci. U.S.A 2005, 102, 1404014045.

5. $\quad$ Guan, Y.; Zheng, B. J.; He, Y. Q.; Liu, X. L.; Zhuang, Z. X.; Cheung, C. L.; Luo, S. W.; Li, P. H.; Zhang, L. J.; Guan, Y. J.; Butt, K. M.; Wong, K. L.; Chan, K. W.; Lim, W.; Shortridge, K. F.; Yuen, K. Y.; Peiris, J. S. M.; Poon, L. L. M., Isolation and Characterization of Viruses Related to the SARS Coronavirus from Animals in Southern China. Science 2003, 302, 276.

6. Huang, C. L.; Wang, Y. M.; Li, X. W.; Ren, L. L.; Zhao, J. P.; Hu, Y.; Zhang, L.; Fan, G. H.; Xu, J. Y.; Gu, X. Y.; Cheng, Z. S.; Yu, T.; Xia, J. A.; Wei, Y.; Wu, W. J.; Xie, X. L.; Yin, W.; Li, H.; Liu, M.; Xiao, Y.; Gao, H.; Guo, L.; Xie, J. G.; Wang, G. F.; Jiang, R. M.; Gao, Z. C.; Jin, Q.; Wang, J. W.; Cao, B., Clinical features of patients infected with 2019 novel coronavirus in Wuhan, China. Lancet 2020, 395, 497-506.

7. Wang, C.; Horby, P. W.; Hayden, F. G.; Gao, G. F., A novel coronavirus outbreak of global health concern. Lancet 2020, 395, 470-473. 
8. Yu Wai, C.; Chin-Pang, Y.; Kwok-Yin, W., Prediction of the SARS-CoV-2 (2019-nCoV) 3C-like Protease (3CLpro) Structure: Virtual Screening Reveals Velpatasvir, Ledipasvir, and Other Drug Repurposing Candidates. F1000Res 2020, 9, 129.

9. Zhou, P.; Yang, X.-L.; Wang, X.-G.; Hu, B.; Zhang, L.; Zhang, W.; Si, H.-R.; Zhu, Y.; Li, B.; Huang, C.-L.; Chen, H.-D.; Chen, J.; Luo, Y.; Guo, H.; Jiang, R.-D.; Liu, M.-Q.; Chen, Y.; Shen, X.-R.; Wang, X.; Zheng, X.-S.; Zhao, K.; Chen, Q.-J.; Deng, F.; Liu, L.-L.; Yan, B.; Zhan, F.-X.; Wang, Y.-Y.; Xiao, G.-F.; Shi, Z.-L., A Pneumonia Outbreak Associated with a New Coronavirus of Probable Bat Origin. Nature 2020, 579, 270-273.

10. Chan, J. F. W.; Yuan, S. F.; Kok, K. H.; To, K. K. W.; Chu, H.; Yang, J.; Xing, F. F.; Liu, J. L.; Yip, C. C. Y.; Poon, R. W. S.; Tsoi, H. W.; Lo, S. K. F.; Chan, K. H.; Poon, V. K. M.; Chan, W. M.; Ip, J. D.; Cai, J. P.; Cheng, V. C. C.; Chen, H. L.; Hui, C. K. M.; Yuen, K. Y., A Familial Cluster of Pneumonia Associated with the 2019 Novel Coronavirus Indicating Person-to-Person Transmission: a Study of a Family Cluster. Lancet 2020, 395, 514-523.

11. WHO Coronavirus disease 2019 (COVID-19) Situation Report - 52.

12. Schoeman, D.; Fielding, B. C., Coronavirus envelope protein: current knowledge. Virology 2019, 16, 69.

13. Fauquet, C. M.; Fargette, D., International Committee on Taxonomy of Viruses and the 3,142 unassigned species. Virology 2005, 2, 64.

14. Zhang, L.; Lin, D.; Sun, X.; Curth, U.; Drosten, C.; Sauerhering, L.; Becker, S.; Rox, K.; Hilgenfeld, R., Crystal Structure of SARS-CoV-2 Main Protease Provides a Basis for Design of Improved $\alpha$-Ketoamide Inhibitors. Science 2020, 368, 409-412.

15. Nukoolkarn, V.; Lee, V. S.; Malaisree, M.; Aruksakulwong, O.; Hannongbua, S., Molecular Dynamic Simulations Analysis of Ritronavir and Lopinavir as SARS-CoV 3CLpro Inhibitors. J. Theor. Biol. 2008, 254, 861-867.

16. Efficacy and Safety of Darunavir and Cobicistat for Treatment of Pneumonia Caused by 2019-nCoV (DACO-nCoV). https://clinicaltrials.gov/ct2/show/NCT04252274 (accessed Mar 8).

17. A Randomized,Open,Controlled Clinical Study to Evaluate the Efficacy of ASC09F and Ritonavir for 2019-nCoV Pneumonia. https://clinicaltrials.gov/ct2/show/NCT04261270 (accessed Mar 8).

18. Marshall, G. R., Computer-Aided Drug Design. Ann. Rev. Pharmacol. Toxicol. 1987, 27, 193-213.

19. Yu, W.; MacKerell, A. D., Computer-Aided Drug Design Methods. In Antibiotics: Methods and Protocols, Sass, P., Ed. Springer New York: New York, NY, 2017; pp 85-106.

20. Ryde, U.; Soderhjelm, P., Ligand-Binding Affinity Estimates Supported by QuantumMechanical Methods. Chem Rev 2016, 116, 5520-5566.

21. Gehlhaar, D. K.; Verkhivker, G.; Rejto, P. A.; Fogel, D. B.; Fogel, L. J.; Freer, S. T., Docking Conformationally Flexible Small Molecules into a Protein Binding Site through Evolutionary Programming. In Proceedings of the Fourth International Conference on Evolutionary Programming: 1-3 March 1995; San Diego, John R, M. D.; Robert G, R.; David B, F., Eds. MIT Press: 1995.

22. Kollman, P. A.; Massova, I.; Reyes, C.; Kuhn, B.; Huo, S.; Chong, L.; Lee, M.; Lee, T.; Duan, Y.; Wang, W.; Donini, O.; Cieplak, P.; Srinivasan, J.; Case, D. A.; Cheatham, T. E., Calculating structures and free energies of complex molecules: combining molecular mechanics and continuum models. Acc. Chem. Res. 2000, 33, 889-897.
Formatted: Font: (Default) Times New Roman, 12 pt

Formatted: Font: (Default) Times New Roman, 12 pt

Formatted: Font: (Default) Times New Roman, 12 pt

Formatted: Font: (Default) Times New Roman, 12 pt 
23. Kuhn, B.; Kollman, P. A., Binding of a siverse set of ligands to avidin and streptavidin: an accurate quantitative prediction of their relative affinities by a combination of molecular mechanics and continuum solvent models. J. Med. Chem. 2000, 43, 3786-3791.

24. Wang, W.; Kollman, P. A., Computational study of protein specificity: the molecular basis of HIV-1 protease drug resistance. Proc. Natl. Acad. Sci. USA 2001, 98, 14937-14942.

25. Aqvist, J.; Medina, C.; Samuelsson, J.-E., A New Method for Predicting Binding Affinity in Computer-Aidded Drug Design. Protein Eng. 1994, 7, 385-391.

26. Jones-Hertzog, D. K.; Jorgensen, W. L., Binding Affinities for Sulfonamide Inhibitors with Human Thrombin Using Monte Carlo Simulations with a Linear Response Method. J. Med. Chem. 1997, 40, 1539-1549.

27. Ngo, S. T.; Hung, H. M.; Nguyen, M. T., Fast and Accurate Determination of the Relative Binding Affinities of Small Compounds to HIV-1 Protease using Non-Equilibrium Work. J. Comput. Chem. 2016, 37, 2734-2742.

28. Zwanzig, R. W., High-temperature equation of state by a perturbation method. I. Nonpolar gases. J. Chem. Phys. 1954, 22, 1420-1426.

29. Beveridge, D. L.; DiCapua, F. M., Free energy via molecular simulation: applications to chemical and biomolecular systems. Annu. Rev. Biophys. Biophys. Chem. 1989, 18, 431-492.

30. Kirkwood, J. G., Statistical Mechanics of Fluid Mixtures. J. Chem. Phys. 1935, 3, 300-313.

31. Kollman, P., Free energy calculations: applications to chemical and biochemical phenomena. Chem. Rev. 1993, 93, 2395-2417.

32. Jarzynski, C., Equilibrium free-energy differences from nonequilibrium measurements: A master-equation approach. Phys Rev E 1997, 56, 5018-5035.

33. Jiang, W.; Roux, B., Free Energy Perturbation Hamiltonian Replica-Exchange Molecular Dynamics (FEP/H-REMD) for Absolute Ligand Binding Free Energy Calculations. J. Chem. Theory Comput. 2010, 6, 2559-2565.

34. Meng, Y.; Sabri Dashti, D.; Roitberg, A. E., Computing Alchemical Free Energy Differences with Hamiltonian Replica Exchange Molecular Dynamics (H-REMD) Simulations. $J$. Chem. Theory Comput. 2011, 7, 2721-2727.

35. Jiang, W.; Thirman, J.; Jo, S.; Roux, B., Reduced Free Energy Perturbation/Hamiltonian Replica Exchange Molecular Dynamics Method with Unbiased Alchemical Thermodynamic Axis. J. Phys. Chem. B 2018, 122, 9435-9442.

36. Ngo, S. T.; Nguyen, T. H.; Tung, N. T.; Nam, P. C.; Vu, K. B.; Vu, V. V., Oversampling Free Energy Perturbation Simulation in Determination of the Ligand-Binding Free Energy. J. Comput. Chem 2020, 41, 611-618.

37. Christian C., G.; Georg, S. Wuhan coronavirus 2019-nCoV - what we can find out on a structural bioinformatics level 2020. https://figshare.com/articles/innophore-com-2019ncov_2020-01-29_pdf/11752749.

38. Schrödinger LLC, P. The PyMOL molecular graphics system, Versiol 1.3r1; August, 2010.

39. Trott, O.; Olson, A. J., Improving the speed and accuracy of docking with a new scoring function, efficient optimization, and multithreading. J. Comput. Chem. 2010, 31, 455-461.

40. Nguyen, N. T.; Nguyen, T. H.; Pham, T. N. H.; Huy, N. T.; Bay, M. V.; Pham, M. Q.; Nam, P. C.; Vu, V. V.; Ngo, S. T., Autodock Vina Adopts More Accurate Binding Poses but Autodock4 Forms Better Binding Affinity. J. Chem. Inf.Model. 2020, 60, 204-211.

41. Morris, G. M.; Huey, R.; Lindstrom, W.; Sanner, M. F.; Belew, R. K.; Goodsell, D. S.; Olson, A. J., AutoDock4 and AutoDockTools4: Automated docking with selective receptor flexibility. J. Comput. Chem. 2009, 30, 2785-2791. 
42. Gasteiger, J.; Marsili, M., New Model for Calculating Atomic Charges in Molecules. Tetrahedron Lett 1978, 19.

43. Gasteiger, J.; Marsili, M., Iterative Partial Equalization of Orbital Electronegativity-A Rapid Cccess to Atomic Charges. Tetrahedron 1980, 36, 3219-3228.

44. Forli, S.; Huey, R.; Pique, M. E.; Sanner, M. F.; Goodsell, D. S.; Olson, A. J., Computational protein-ligand docking and virtual drug screening with the AutoDock suite. Nat. Protoc. 2016, 11, 905.

45. Lee, T.-W.; Cherney, M. M.; Huitema, C.; Liu, J.; James, K. E.; Powers, J. C.; Eltis, L. D.; James, M. N. G., Crystal Structures of the Main Peptidase from the SARS Coronavirus Inhibited by a Substrate-like Aza-peptide Epoxide. J. Mol. Biol. 2005, 353, 1137-1151.

46. Abraham, M. J.; Murtola, T.; Schulz, R.; Páll, S.; Smith, J. C.; Hess, B.; Lindahl, E., GROMACS: High performance molecular simulations through multi-level parallelism from laptops to supercomputers. SoftwareX 2015, 1-2, 19-25.

47. Aliev, A. E.; Kulke, M.; Khaneja, H. S.; Chudasama, V.; Sheppard, T. D.; Lanigan, R. M., Motional Timescale Predictions by Molecular Dynamics Simulations: Case Study using Proline and Hydroxyproline Sidechain Dynamics. Proteins: Struct., Funct., Bioinf. 2014, 82, 195215.

48. Wang, Y.; Xiao, J.; Suzek, T. O.; Zhang, J.; Wang, J.; Zhou, Z.; Han, L.; Karapetyan, K.; Dracheva, S.; Shoemaker, B. A.; Bolton, E.; Gindulyte, A.; Bryant, S. H., PubChem's BioAssay Database. Nucleic Acids Res 2012, 40, D400-D412.

49. Wang, J.; Wang, W.; Kollman, P. A.; Case, D. A., Automatic Atom Type and Bond Type Perception in Molecular Mechanical Calculations. J Mol Graph Model 2006, 25, 247-260.

50. Case, D. A.; Ben-Shalom, I. Y.; Brozell, S. R.; Cerutti, D. S.; Cheatham, T. E. C., III, V.W.D. ; Darden, T. A.; Duke, R. E.; Ghoreishi, D.; Gilson, M. K.; Gohlke, H.; Goetz, A. W.; Greene, D.; Harris, R.; Homeyer, N.; Huang, Y.; Izadi, S.; Kovalenko, A.; Kurtzman, T.; Lee, T. S.; LeGrand, S.; Li, P.; Lin, C.; Liu, J.; Luchko, T.; Luo, R.; Mermelstein, D. J.; Merz, K. M.; Miao, Y.; Monard, G.; Nguyen, C.; Nguyen, H.; Omelyan, I.; Onufriev, A.; Pan, F.; Qi, R.; Roe, D. R.; Roitberg, A.; Sagui, C.; Schott-Verdugo, S.; Shen, J.; Simmerling, C. L.; Smith, J.; SalomonFerrer, R.; Swails, J.; Walker, R. C.; Wang, J.; Wei, H.; Wolf, R. M.; Wu, X.; Xiao, L.; D.M., Y.; P.A., a. K., AMBER 18. University of California, San Francisco 2018.

51. Sousa da Silva, A. W.; Vranken, W. F., ACPYPE - AnteChamber PYthon Parser interfacE. BMC Research Notes 2012, 5, 1-8.

52. Wang, J.; Wolf, R. M.; Caldwell, J. W.; Kollman, P. A.; Case, D. A., Development and Testing of a General Amber Force Field. J. Comput. Chem. 2004, 25, 1157-1174.

53. Darden, T.; York, D.; Pedersen, L., Particle mesh Ewald: An N·log(N) method for Ewald sums in large systems. J. Chem. Phys. 1993, 98, 10089-10092.

54. Zwanzig, R. W., High-temperature equation of state by a perturbation method. I. nonpolar gases. J. Chem. Phys. 1954, 22, 1420-1426.

55. Bennett, C. H., Efficient estimation of free energy differences from Monte Carlo data. $J$. Comput. Phys. 1976, 22, 245-268.

56. Laskowski, R. A.; Swindells, M. B., LigPlot+: Multiple Ligand-Protein Interaction Diagrams for Drug Discovery. J. Chem. Inf. Model. 2011, 51, 2778-2786.

57. S.K. Lee; I.H. Lee; H.J. Kim; G.S. Chang; J.E. Chung; No, K. T., The PreADME approach: Web-based program for rapid prediction of physico-chemical, drug absorption and druglike properties, EuroQSAR 2002 Designing Drugs and Crop Protectants: Processes, Problems and 
Solutions. Blackwell Publishing: Maldenh, MA, 2003; pp. 418-420. http://dx.doi.org/10.1002/cphc.201701384.

58. Nguyen-Vo, T.-H.; Le, T.; Pham, D.; Nguyen, T.; Le, P.; Nguyen, A.; Nguyen, T.; Nguyen, T.-N.; Nguyen, V.; Do, H.; Trinh, K.; Duong, H. T.; Le, L., VIETHERB: A Database for Vietnamese Herbal Species. J. Chem. Inf. Model. 2019, 59, 1-9.

59. Mai, B. K.; Viet, M. H.; Li, M. S., Top-Leads for Swine Influenza A/H1N1 Virus Revealed by Steered Molecular Dynamics Approach. J. Chem. Inf. Model. 2010, 50, 2236-2247.

60. Jarzynski, C., Nonequilibrium Equality for Free Energy Differences. Phys Rev Lett 1997, 78, 2690-2693.

61. Park, S.; Schulten, K., Calculating Potentials of Mean Force from Steered Molecular Dynamics Simulations. J. Chem. Phys. 2004, 120, 5946-5961.

62. Alex, Z.; Vladimir, A.; Alexander, Z.; Bogdan, Z.; Victor, T.; Dmitry S., B.; Daniil, P.; Rim, S.; Andrey, F.; Philipp, O.; Yilin, Y.; Olga, P.; Quentin, V.; Alex, A.; Yan, I., Potential COVID-2019 3C-like Protease Inhibitors Designed Using Generative Deep Learning Approaches. 2020.

63. Cao, B.; Wang, Y.; Wen, D.; Liu, W.; Wang, J.; Fan, G.; Ruan, L.; Song, B.; Cai, Y.; Wei, M.; Li, X.; Xia, J.; Chen, N.; Xiang, J.; Yu, T.; Bai, T.; Xie, X.; Zhang, L.; Li, C.; Yuan, Y.; Chen, H.; Li, H.; Huang, H.; Tu, S.; Gong, F.; Liu, Y.; Wei, Y.; Dong, C.; Zhou, F.; Gu, X.; Xu, J.; Liu, Z.; Zhang, Y.; Li, H.; Shang, L.; Wang, K.; Li, K.; Zhou, X.; Dong, X.; Qu, Z.; Lu, S.; Hu, X.; Ruan, S.; Luo, S.; Wu, J.; Peng, L.; Cheng, F.; Pan, L.; Zou, J.; Jia, C.; Wang, J.; Liu, X.; Wang, S.; Wu, X.; Ge, Q.; He, J.; Zhan, H.; Qiu, F.; Guo, L.; Huang, C.; Jaki, T.; Hayden, F. G.; Horby, P. W.; Zhang, D.; Wang, C., A Trial of LopinavirRitonavir in Adults Hospitalized with Severe Covid-19. N Engl J Med 2020.

64. Homeyer, N.; Stoll, F.; Hillisch, A.; Gohlke, H., Binding Free Energy Calculations for Lead Optimization: Assessment of Their Accuracy in an Industrial Drug Design Context. J. Chem. Theory Comput. 2014, 10, 3331-3344.

65. Nascimento, É. C. M.; Oliva, M.; Świderek, K.; Martins, J. B. L.; Andrés, J., Binding Analysis of Some Classical Acetylcholinesterase Inhibitors: Insights for a Rational Design Using Free Energy Perturbation Method Calculations with QM/MM MD Simulations. J. Chem. Inf. Model. 2017, 57, 958-976.

66. Ngo, S. T.; Fang, S.-T.; Huang, S.-H.; Chou, C.-L.; Huy, P. D. Q.; Li, M. S.; Chen, Y.C., Anti-Arrhythmic Medication Propafenone a Potential Drug for Alzheimer's Disease Inhibiting Aggregation of A $\beta$ : In Silico and In Vitro Studies. J. Chem. Inf. Model. 2016, 56, 1344-1356.

67. Ciordia, M.; Pérez-Benito, L.; Delgado, F.; Trabanco, A. A.; Tresadern, G., Application of Free Energy Perturbation for the Design of BACE1 Inhibitors. J. Chem. Inf. Model. 2016, 56, 1856-1871.

68. Tran, P.-T.; Hoang, V.-H.; Lee, J.; Hien, T. T. T.; Tung, N. T.; Ngo, S. T., In vitro and in silico determination of glutaminyl cyclase inhibitors. RSC Adv 2019, 9, 29619-29627.

69. Sakakibara, I.; Katsuhara, T.; Ikeya, Y.; Hayashi, K.; Mitsuhashi, H., Cannabisin A, an arylnaphthalene lignanamide from fruits of Cannabis sativa. Phytochemistry 1991, 30, 3013-3016. 
Table of Contents Only

\begin{tabular}{|c|c|c|}
\hline $\begin{array}{c}\text { Son Tung Ngo, Ngoc } \\
\text { Quynh Anh Pham, } \\
\text { Ly Le, Duc-Hung } \\
\text { Pham, and Van V. } \\
\text { Vu }\end{array}$ & $\begin{array}{c}\text { Computational Determination } \\
\text { of Potential Inhibitors of SARS- } \\
\text { CoV-2 Main Protease }\end{array}$ \\
\hline
\end{tabular}

